\title{
Utilisation of Blood Components in Trauma Surgery: A Single-Centre, Retrospective Analysis before and after the Implementation of an Educative PBM Initiative
}

\author{
Raoul Georg Geissler ${ }^{a} \quad$ Clemens Kösters $^{b} \quad$ Dominik Franz ${ }^{c} \quad$ Hubert Buddendick $^{c}$ \\ Matthias Borowski ${ }^{d}$ Christian Juhra $^{b}$ Matthias Lange ${ }^{e}$ Holger Bunzemeier ${ }^{c}$ \\ Norbert Roeder ${ }^{\mathrm{f}}$ Walter Sibrowski ${ }^{a}$ Michael J. Raschke ${ }^{\mathrm{b}}$ Peter Schlenke $^{\mathrm{a}, \mathrm{g}}$

\footnotetext{
a Institute for Transfusion Medicine and Transplantation Immunology, University Hospital of Münster, Münster, Germany;

${ }^{b}$ Department of Trauma, Hand and Reconstructive Surgery, University Hospital of Münster, Münster, Germany;

${ }^{c}$ DRG Research Group and Medical Management, University Hospital of Münster, Münster, Germany;

${ }^{d}$ Institute for Biostatistics and Clinical Research, University of Münster, Münster, Germany;

${ }^{\mathrm{e}}$ Institute for Anaesthesiology, Surgical Intensive Care and Pain Therapy, University Hospital of Münster, Münster, Germany;

${ }^{f}$ Board of the Hospital, University Hospital of Münster, Münster, Germany;
} \\ ${ }^{9}$ Department of Blood Group Serology and Transfusion Medicine, Medical University Graz, Graz, Austria
}

\section{Keywords}

Trauma surgery - Patient blood management .

Blood supply · Haemotherapy · Health services research

\section{Summary}

Background: The aim of our single-centre retrospective study presented here is to further analyse the utilisation of allogeneic blood components within a 5-year observation period (2009-2013) in trauma surgery $(15,457$ patients) under the measures of an educational patient blood management (PBM) initiative. Methods: After the implementation of the PBM initiative in January 2012, the Institute of Transfusion Medicine und Transplantation Immunology educates surgeons and nurses at the Department of Trauma Surgery to avoid unnecessary blood transfusions. A standardised reporting system was used to document the utilisation of blood components carefully for the most frequent diagnoses and surgical interventions in trauma surgery. These measures served as basis for the implementation of an interdisciplinary systematic exchange of information to foster decision-making processes in favour of patient blood management. Results: Since January 2012, the proportion of patients who received a transfusion as well as the number of transfused red blood cell (RBC) $(7.3 \% / 6.4 \%$; $\mathrm{p}=0.02)$, fresh frozen plasma (FFP) $(1.7 \% / 1.3 \% ; \mathrm{p}<0.05)$ and platelet (PLT) $(1.0 \% / 0.5 \% ; p<0.001)$ units were re- duced as a result of our PBM initiative. However, among the transfused patients, the number of administered RBC, FFP and PLT units did not decrease significantly. Overall, patients who did not receive transfusions were younger than transfused patients $(p=0.001)$. The subgroup with the highest probability of blood transfusion administered included patients with intensive care and long-term ventilation (before/after implementation of PBM: RBC $81.5 \% / 75.9 \%$; FFP $33.3 \% / 20.4 \%$; PLT $24.1 \% / 13.0 \%$ ). Only a total of 60 patients of 531 patients suffering multiple traumas were massively transfused (before/after implementation of PBM: RBC 55.6\%/49.8\%; FFP 28.4\%/20.4\%; PLT 17.6\%/8.9\%). Conclusion: According to our educational PBM initiative, at least the proportion of trauma patients who received allogeneic blood transfusions could be reduced significantly. However, in case of blood transfusions, the total consumption of RBC, FFP and PLT units remained stable in both time periods. This phenomenon might indicate that the actual need of blood transfusions rather depends on the severity of trauma-related blood loss, the coagulopathy rates or the complexity of the surgical intervention which mainly determines the intra-operative blood loss. Taken together, educational training sessions and systematic reporting systems are suitable measures to avoid unnecessary allogeneic blood transfusions and to continuously improve their restrictive application.

\section{KARGER}

Fax +497614520714
() 2015 S. Karger GmbH, Freiburg

$1660-3796 / 15 / 0422-0083 \$ 39.50 / 0$
PD Dr. Raoul Georg Geissler

Institut für Transfusionsmedizin und Transplantationsimmunologie

Universitätsklinikum Münster

Domagkstraße 11, 48149 Münster, German

georg.geissler@ukmuenster.d 


\section{Introduction}

The German TraumaNetwork DGU ${ }^{\circledR}$ Project was initiated in 2006 to improve the pre-hospital rescue system of seriously injured patients, to accelerate their transfer to an appropriate hospital and to compensate for variations in the hospital infrastructure, personal strength and equipment [1]. Dividing the participating hospitals into local, regional and supra-regional trauma surgical centres, this new quality emergency system reached full coverage throughout Germany in 2012. Furthermore, a new interdisciplinary S3 guideline was published to optimise the patient outcome in pre-hospital and emergency room care as well as in emergency surgery [2]. In 2011, about 8.72 million people are injured and more than 20,406 die in accidents in Germany [3]. Only a minor subset of these patients requires blood components. To predict transfusion requirements in those seriously injured patients, an emergency transfusion score comprising three different clinical risk groups was implemented $[4,5]$.

Especially extensive and complex injuries are the cause of frequent blood transfusions to compensate for major blood loss [615]. The severity and nature of the injuries directly influence the likelihood and volume of blood transfusions. Therefore, a central task in emergency medicine is to rapidly control haemorrhage to ensure the survival of injured patients $[9,12,13,16-19]$. Additionally, the time of transportation, the risks of hypothermia and trauma-induced coagulopathies as well as age and co-morbidities of each individual patient are further confounding determinants of the need for blood transfusion $[9,16]$.

The Department of Trauma Surgery at the University Hospital Münster (UKM) is one of the supra-regional trauma centres within the German TraumaNetwork DGU with frequent demand of blood components [20]. The aim of this single-centre retrospective study was to analyse the utilisation of blood components in trauma patients, focusing on the comparison of the transfusion frequency and intensity before and after the implementation of a patient blood management (PBM) initiative which was based primarily on an educational training programme. Fortunately, our database structure allowed the precise linkage of blood transfusions to trauma diagnoses and surgical treatments with special emphasis on multiple trauma patients.

\section{Material and Methods}

\section{Database}

The Institute of Transfusion Medicine and Transplantation Immunology documents each transfusion of allogeneic blood components on a per-case basis for all in-patients, including number of transfused red blood cells (RBCs), fresh frozen plasma (FFP) and platelets (PLTs), date of production and issuance, diagnosis, surgical/non-surgical procedures as well as clinical performance groups (klinische Leistungsgruppen $=\mathrm{KLG}$ ).

\section{Data Processing}

The case-related patient data are allocated to the particular medical department within a standardised process developed by the Department of Medical Management $[21,22]$. This allocation is done using an algorithm that assures a comprehensible and reliable assignment of cases to enable the medical department and the hospital management to plan, monitor and control the number of operations during in-patient treatment and is based mainly on the complexity of a surgical procedure and the length of stay [21, 22]. After allocation to the main treating medical department, the case-related data undergo a further classification and were assigned to the KLG. [21]. The KLG system is mostly independent from the German diagnosis related groups (G-DRG) system. Within the KLG system, each in-patient case is assigned to only one KLG, e.g., multiple trauma, intensive care with long-term ventilation or arthroplasty. If necessary, the KLG are further differentiated into subclasses, e.g., arthroplasty is subdivided into modular prosthesis, knee or hip or other joint prosthesis, and prosthesis replacement. The allocation process follows a given hierarchy that considers complex cases first, e.g., multiple trauma. Cases of lower complexity or non-surgical treatments are accounted in descending order. The KLG for multiple traumas used in this study comprises all cases that are identified as 'multiple trauma' in terms of the G-DRG system (at least two serious injuries of different body sites) as well as cases with serious injuries as main diagnosis with artificial ventilation of more than $249 \mathrm{~h}$. In contrast, the KLG for 'intensive care with long-term ventilations' includes all cases that do not fulfil the requirements of the function 'multiple trauma' but require treatment in an intensive care unit (ICU) and artificial ventilation for more than $95 \mathrm{~h}$.

\section{PBM Initiative}

Since January 2012, the Department of Trauma Surgery and all other departments in the UKM have been subject to regular reporting and educational training sessions about the utilisation of blood components (RBCs, FFP, PLTs) by the Institute of Transfusion Medicine and Transplantation Immunology. The standardised report contains all transfusion requirements corresponding to each KLG mentioned above. The data even enable us to retrace decision-making in favour of blood transfusion in individual patients if necessary. The report serves as a basis to enable the transfusion-commissioned physician to critically scrutinising his/her blood utilisation practise and to acquaint him/her with the ideas of worldwide PBM initiatives. Currently used indications for blood transfusions and the adherence to rather restrictive transfusion policies published in the German guidelines were selected as central topics. Suggestions for improvement, e.g., elective operations, blood-saving methods or massive transfusions, are developed and realised together with the department.

Additionally, standardised PBM training programmes for doctors and nurses are performed regularly, particularly with aim to avoid overuse of blood transfusions in trauma surgery and, at least, to guarantee compliance to the recommendations of the German guidelines.

\section{Statistical Methods}

The comparison of time periods was performed using Fisher's exact test [23] for qualitative variables with two categories, the chi-square test [24] for qualitative variables with three or more categories and the Mann-Whitney-U-test [25] for quantitative variables. All tests were two-sided. If a p value was smaller than $5 \%$, we concluded that the difference was statistically noticeable. We intentionally do not use the term 'significant'. Because this is a retrospective analysis, the results of the statistical tests are to be interpreted in an exploratory, and not in a confirmatory sense, and an adjustment for multiple testing is not applied.

\section{Results}

Approximately $6 \%$ of all in-patients of the UKM were treated in the Department of Trauma Surgery annually. This patient cohort incorporated 15,457 individuals (2009-2013) which consumed per annum $5.0-5.9 \%$ of RBCs, $2.7-4.8 \%$ of FFP and $0.7-1.7 \%$ of PLTs of all units transfused in the UKM (table 1). Not surprisingly, trauma patients required more units of RBCs than of FFP or PLTs as indicated by an RBC/FFP ratio of $\sim 2$ and an $\mathrm{RBC} / \mathrm{PLT}$ ratio of $\sim 15$. 
Table 1. Frequency of transfused patients and of transfusions in trauma surgery

\begin{tabular}{|c|c|c|c|c|c|c|c|c|c|}
\hline \multirow[t]{2}{*}{ Year (number of patients) } & \multicolumn{3}{|l|}{ RBCs } & \multicolumn{3}{|l|}{ FFP } & \multicolumn{3}{|l|}{ PLTs } \\
\hline & Tf. Pat. (\%) & units & $\begin{array}{l}\text { median } \\
\text { (IQR) }\end{array}$ & Tf. Pat. (\%) & units & $\begin{array}{l}\text { median } \\
(\mathrm{IQR})\end{array}$ & Tf. Pat. (\%) & units & $\begin{array}{l}\text { median } \\
\text { (IQR) }\end{array}$ \\
\hline $2009(2,874)$ & $183(6.4 \%)$ & 1,308 & $4(4)$ & $41(1.4 \%)$ & 787 & $8(14)$ & $27(0.9 \%)$ & 108 & $2(3)$ \\
\hline $2010(2,943)$ & $212(7.2 \%)$ & 1,333 & $4(5)$ & $58(2.0 \%)$ & 673 & $8(6)$ & $34(1.2 \%)$ & 103 & $2(2)$ \\
\hline $2011(3,091)$ & $251(8.1 \%)$ & 1,414 & $4(4)$ & $56(1.8 \%)$ & 697 & $8(4.2)$ & $31(1.0 \%)$ & 104 & $2(2.5)$ \\
\hline$\Sigma 2009-2011(8,908)$ & $646(7.3 \%)$ & 1,352 & $4(4)$ & $155(1.7 \%)$ & 719 & $8(8.5)$ & $92(1.0 \%)$ & 105 & $2(2)$ \\
\hline $2012^{\star}(3,186)$ & $188(5.9 \%)$ & 1,237 & $4(6)$ & $41(1.3 \%)$ & 443 & $8(6)$ & $19(0.6 \%)$ & 68 & $2(3)$ \\
\hline $2013^{*}(3,363)$ & $232(6.9 \%)$ & 1,245 & $3(4)$ & $41(1.2 \%)$ & 610 & $6(6)$ & $15(0.4 \%)$ & 44 & $1(2.5)$ \\
\hline$\sum 2012-2013^{*}(6,549)$ & $420(6.4 \%)$ & 1,241 & $4(4)$ & $82(1.3 \%)$ & 527 & $8(6)$ & $34(0.5 \%)$ & 56 & $2(3)$ \\
\hline
\end{tabular}

Tf. Pat. = Absolute number of transfused patients; units = transfused units; IQR = inter quartile range (difference between the $75 \%$ and the $25 \%$ quantile). ${ }^{*} \mathrm{PBM}$ initiative started in 2012 .

Table 2. Patient cohorts without/with blood transfusions in trauma surgery

\begin{tabular}{|c|c|c|c|c|c|}
\hline & No units (\%) & $1-2$ units (\%) & $>2$ units $(\%)^{\star *}$ & & $\sum$ of all cases \\
\hline \multicolumn{6}{|l|}{$\mathrm{RBCs}^{* *}$} \\
\hline 2009-2011 & $8,262(92.7 \%)$ & $243(2.7 \%)$ & 403 (4.5\%) & & 8,908 \\
\hline $2012-2013^{*}$ & $6,129(93.6 \%)$ & $182(2.8 \%)$ & $238(3.6 \%)$ & & 6,549 \\
\hline \multirow[t]{2}{*}{$\sum$ of all cases } & 14,391 & 425 & 641 & & 15,457 \\
\hline & No units (\%) & $1-4$ units (\%) & $5-10$ units $(\%)^{* *}$ & $>10$ units $(\%)^{\star *}$ & \\
\hline \multicolumn{6}{|l|}{$\mathrm{FFP}^{\star *}$} \\
\hline 2009-2011 & $8,753(98.3 \%)$ & $15(0.2 \%)$ & $90(1.0 \%)$ & $50(0.6 \%)$ & 8,908 \\
\hline $2012-2013^{*}$ & 6,467 (98.7\%) & $13(0.2 \%)$ & $43(0.7 \%)$ & $26(0.4 \%)$ & 6,549 \\
\hline \multirow[t]{2}{*}{$\sum$ of all cases } & 15,220 & 28 & 133 & 76 & 15,457 \\
\hline & No units (\%) & $1-2$ units $(\%)^{* *}$ & $>2$ units $(\%)$ & & \\
\hline \multicolumn{6}{|l|}{$\mathrm{PLTs}^{* *}$} \\
\hline 2009-2011 & $8,816(99.0 \%)$ & $61(0.7 \%)$ & $31(0.3 \%)$ & & 8,908 \\
\hline $2012-2013^{\star}$ & $6,515(99.5 \%)$ & $20(0.3 \%)$ & $14(0.2 \%)$ & & 6,549 \\
\hline$\sum$ of all cases & 15,331 & 81 & 45 & & 15,457 \\
\hline
\end{tabular}

${ }^{*}$ PBM initiative started in January 2012

${ }^{*}$ Statistically noticeable difference using chi square test (RBCs $\mathrm{p}=0.02$; FFP $\mathrm{p}<0.05$; PLTs $\left.\mathrm{p}<0.01\right)$.
Our PBM initiative started in January 2012. The overall frequency of trauma patients receiving RBC, FFP and PLT units before and after the PBM implementation was low $(<8 \%$ for RBCs, $<2 \%$ for FFP and $\leq 1 \%$ for PLTs as shown in table 2 in more detail). A statistically noticeable difference in favour of a lower probability to become transfused was observed in most patients with a hospital stay after PBM implementation, e.g. for those with $>2$ RBC ( $p=$ $0.023), \geq 5$ FFP $(p=0.049)$ and 1-2 PLT ( $=0.002)$ transfusions.

Considering only the above mentioned minor patient cohort which received one blood transfusion, the total number of transfused RBC, FFP, and PLT units did not change considerably (fig. 1). The median consumption of RBC, FFP and PLT units was equal in both time periods (RBCs 4, FFP 8, PLTs 2), and a statistically noticeable difference cannot be observed (RBCs $p=0.076$, FFP $p=0.342$, PLTs $p=0.959$ ), although there was a trend towards a reduction of $\mathrm{RBC}$ transfusion. The boxplots also reveal that the vast majority of trauma patients - in the case that any transfusion was applied - received $\geq 5$ FFP and up to 4 PLTs (fig. 1). Furthermore, only about $16 \%$ of the transfused patients received $\geq 10 \mathrm{RBC}$ units during the hospital stay. We observed that the 'tradition of ordering RBC in double packs' persists as approximately $80 \%$ of the transfused patients received an even number of RBC units.

The age distribution of all trauma patients remained similar after the introduction of our PBM initiative as expected (median 45 and 46 years, fig. 2). Irrespective of PBM measures, we observed that older patients are more likely to receive blood transfusions; e.g., the median age for RBC transfusions was 67 years versus 44 years for the patient cohort without transfusions $(\mathrm{p}=0.001)$. Comparable data for FFP and PLT are summarised in figure 2. Not surprisingly, the proportion of female and male patients within trauma patients did not change after 2011. More men (58\%) than women $(42 \%)$ were admitted to the Department of Trauma Surgery, but the proportion of patients who were transfused with allogeneic RBCs was noticeably higher $(\mathrm{p}<0.001)$ in women $(8.4 \%)$ 
Transfused RBC

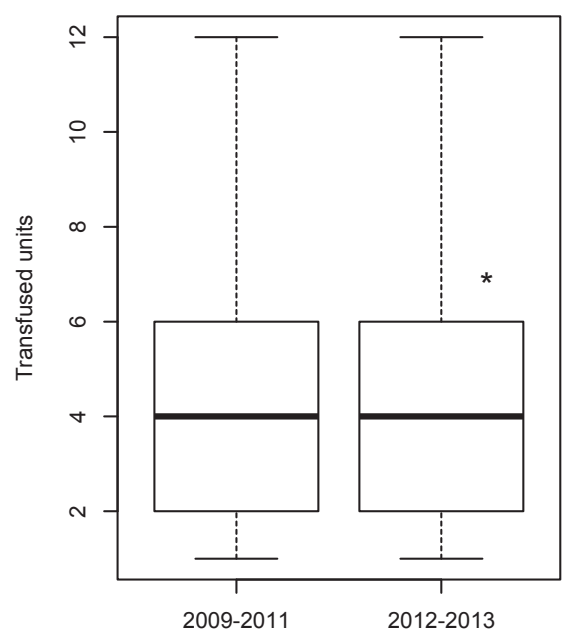

Transfused FFP

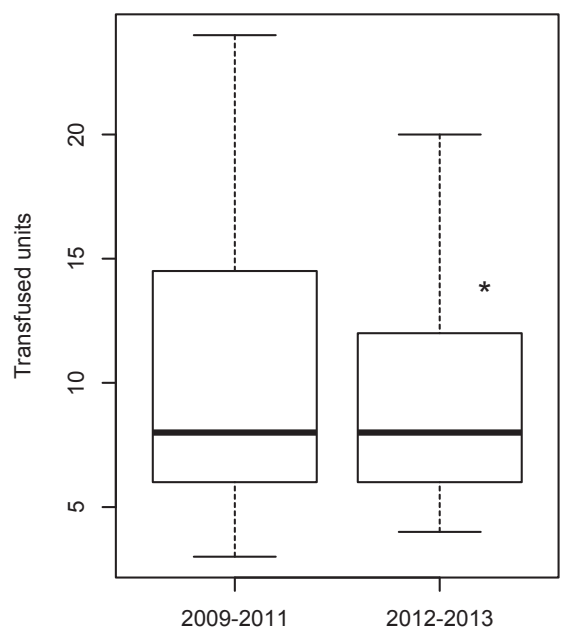

Transfused PLT

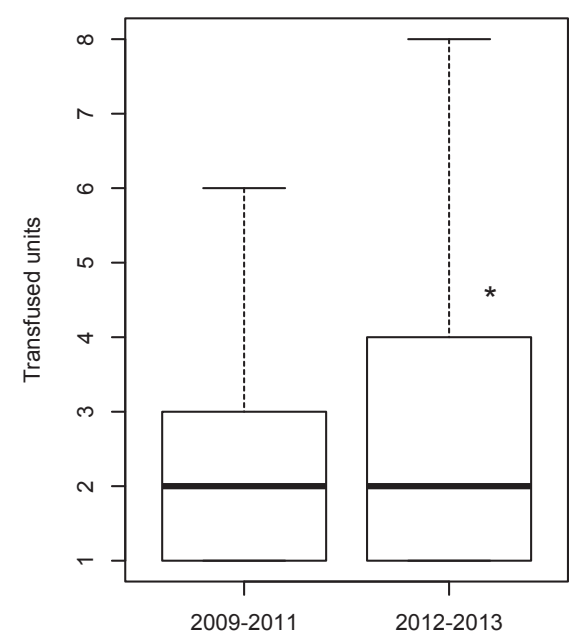

Fig. 1. Amount of blood components transfused in trauma surgery ( ${ }^{*} \mathrm{PBM}$ initiative started in January 2012). No statistically significant differences were observable for RBC, FFP and PLT utilisation before and after the implementation of our PBM initiative. A trend to lower transfusion intensity could be identified for $\operatorname{RBCs}(\mathrm{p}=0.076)$.

All patients

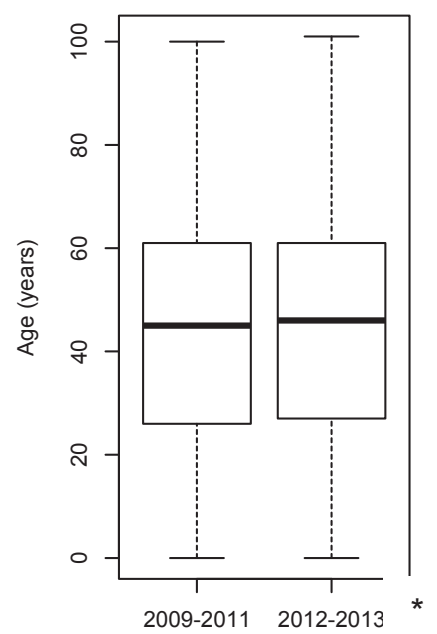

With(out) RBC

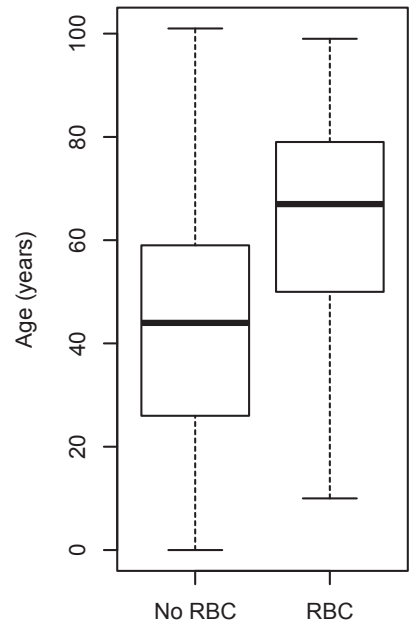

With(out) FFP

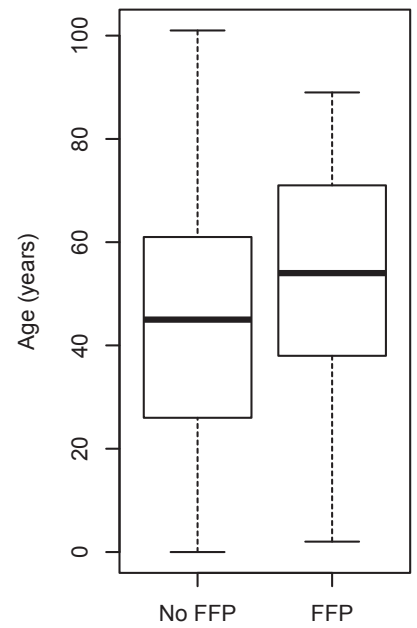

With(out) PLT

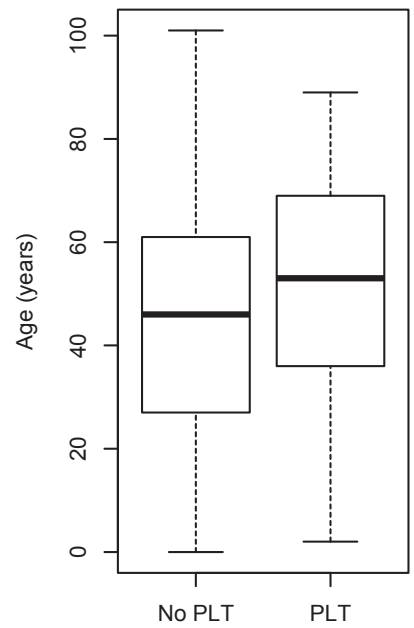

Fig. 2. Age distribution of trauma surgery patients ( ${ }^{*} \mathrm{PBM}$ started in January 2012 ).

than in men (5.9\%). However, if a transfusion was necessary, male trauma patients received a higher number of RBC units (median 4 vs. 3$)$ per treatment than did females $(\mathrm{p}<0.001)$. In contrast, more men than women were transfused with FFP (1.9 vs. $1.0 \%$; $<<$ $0.001)$ and PLTs ( 1.0 vs. $0.6 \% ; \mathrm{p}<0.01)$. However, the median consumption of FFP and PLT units was equal for men and women.

We further investigated whether particular subgroups of trauma patients were transfused more or less frequently. In table 3, the utilisation of blood components is differentiated according to the underlying diagnoses or clinical sub-disciplines of trauma surgery (see 'Material and Methods'). In 2009-2011 and 2012/2013, the cohort of patients with multiple traumas or intensive care with long-term ventilation exhibited a considerably higher rate of blood transfusion recipients and of RBC, FFP and PLT consumption than all other cohorts (e.g., arthroplasty, fracture treatment or bone surgery, operations of spine and spinal cord and several other therapies).

We then focussed on patients with massive transfusions. During the entire observation time, only 173 individuals out of a total of 15,457 patients in the Department of Trauma Surgery were supplied with $\geq 10$ RBC units during their hospital stay, which represents approximately $1 \%$. More than one third of these patients suffered from multiple traumas $(n=60$, table 4 ) with severe haemorrhage and the urgent need of massive transfusion as defined as $\geq 10$ RBC transfusions within $24 \mathrm{~h}$. In other words, only $11.3 \%$ of all patients with multiple traumas required massive transfusions (60/531). Most of these patients were injured by traffic accidents, accidents at work or falls from a great height. In our study, mas- 
Table 3. Trauma surgery: blood utilisation depending on specific diagnoses and procedures

\begin{tabular}{|c|c|c|c|c|c|c|}
\hline & \multicolumn{2}{|l|}{ RBCs } & \multicolumn{2}{|l|}{ FFP } & \multicolumn{2}{|l|}{ PLTs } \\
\hline & 2009-2011 & $2012-2013^{*}$ & 2009-2011 & $2012-2013^{*}$ & 2009-2011 & $2012-2013^{*}$ \\
\hline \multicolumn{7}{|c|}{$\%$ of transfused patients (number of all patients) } \\
\hline Intensive care with long-term ventilation & $81.5 \%(54)$ & $75.9 \%(54)$ & $33.3 \%(54)$ & $20.4 \%(54)$ & $24.1 \%(54)$ & $13.0 \%(54)$ \\
\hline Multiple trauma & $55.6 \%(306)$ & $49.8 \%(225)$ & $28.4 \%(306)$ & $20.4 \%(225)$ & $17.6 \%(306)$ & $8.9 \%(225)$ \\
\hline Arthroplasty & $41.3 \%(334)$ & $35.4 \%(223)$ & $3.9 \%(334)$ & $1.8 \%(223)$ & $1.8 \%(334)$ & $0.4 \%(223)$ \\
\hline Fracture treatment or bone surgery & $6.8 \%(2,647)$ & $5.8 \%(1,834)$ & $0.7 \%(2,647)$ & $0.5 \%(1,834)$ & $0.5 \%(2,647)$ & $0.1 \%(1,834)$ \\
\hline Others $^{\star *}$ & $1.2 \%(5,212)$ & $1.1 \%(3,977)$ & $0.2 \%(5,212)$ & $0.1 \%(3,977)$ & $0.1 \%(5,212)$ & $0.1 \%(3,977)$ \\
\hline \multicolumn{7}{|c|}{ Units of transfused blood components (mean consumption) } \\
\hline Intensive care with long-term ventilation & 11.1 & 10.5 & 16.4 & 9.7 & 5.2 & 3.8 \\
\hline Multiple trauma & 10.7 & 8.8 & 17.1 & 16.8 & 3.7 & 2.8 \\
\hline Arthroplasty & 4.2 & 4.9 & 15.8 & 2.7 & 1.2 & 0.5 \\
\hline Fracture treatment or bone surgery & 4.1 & 3.6 & 7.7 & 6.3 & 2.2 & 9.0 \\
\hline Others ${ }^{* *}$ & 4.1 & 3.8 & 7.6 & 15.4 & 2.1 & 1.3 \\
\hline
\end{tabular}

Table 4. Clinical data of patients with multiple trauma and massive transfusion $(\mathrm{n}=60)$

\begin{tabular}{|c|c|}
\hline Mean age, years (range) & $47(14-85)$ \\
\hline Gender, \% male & 78 \\
\hline \multicolumn{2}{|l|}{ Causes of accidents, $\%$} \\
\hline Traffic ${ }^{*}$ & 67 \\
\hline Fall from a height & 13 \\
\hline At work & 18 \\
\hline Household & 2 \\
\hline \multicolumn{2}{|l|}{ Injuries $\#, \%$} \\
\hline Head \& neck & 55 \\
\hline Face & 23 \\
\hline Chest & 72 \\
\hline Abdomen/pelvis & 70 \\
\hline Extremities & 82 \\
\hline Overall death in hospital, \% & 13 \\
\hline
\end{tabular}

sively transfused patients had an average age of 47 years (range $14-85$ years), and the majority were males (78\%), which is consistent with the well-known observation that men of reproductive age are more often the victims of such accidents. These 60 patients received 1,605 RBC units (mean 27 units, range 10-153 units), 1,588 FFP units (mean 26 units; range 0-151 units) and 252 PLT units (mean 4 units, range $0-38$ units). In our retrospective analysis, two thirds of the multiple traumas were caused by traffic accidents. Approximately $13 \%(8 / 60)$ of patients with multiple traumas and massive transfusions died in the hospital. The referring injury patterns of these patients are presented in table 4 and their injury severity scores (ISS) [26] amounted to 47 on average (in comparison to 12 (range 9.1-15.3) for all trauma patients independent of any blood consumption).

\section{Discussion}

Recently, a great epidemiological study on trauma-related mortality in the USA was published by Sise et al. [27]. Similar to our analysis, the authors identified two main reasons for serious injuries and death: traffic accidents and falls. In contrast to our study, firearm-related injuries and deaths play a further major role for traumarelated mortality in the USA [27]. The mean ISS of all traffic accidents victims admitted to the US emergency centres ranged from 9.3 to 10.3. Our ISS data for patients in the emergency room amounted to 9.1 and 15.3. However, the subgroup of patients with multiple traumas and massive transfusions has a significantly higher ISS, as our data demonstrate (ISS ranged between 16 and 86).

Nowadays, a restrictive strategy of RBC transfusion (haemoglobin $<7 \mathrm{~g} / \mathrm{dl}$ ) is known to be as effective as or even superior to liberal RBC transfusion policies (haemoglobin $<10 \mathrm{~g} / \mathrm{dl}$ ), as initially reported in the landmark TRICC trial by Hébert et al. [28] for critically ill patients, resulting in an about $30 \%$ reduction of allogeneic RBC consumption without negatively affecting the overall mortality. Meanwhile, this observation was confirmed for haemodynamically stable non-bleeding patient cohorts, such as paediatric ICU patients (TRIPICU trial [29]), and for elderly high-risk patients who underwent elective orthopaedic surgery (FOCUS trial [30]). Two further studies support the safety of a rather restrictive transfusion policy in cardiac surgery (TRACS trial [31]) and for patients with upper gastrointestinal bleedings [32] by identifying allogeneic $\mathrm{RBC}$ transfusions as independent risk factor for complications and death. More recently, a Cochrane meta-analysis summarising the results of 19 randomised clinical trials with more than 4,000 surgical patients and several reviews and recommendations have highlighted the impact of blood transfusions on morbidity and mortality $[13,17,33,34]$. However, it remains challenging to implement this restrictive transfusion strategy in severely injured trauma pa- 
tients with ongoing bleedings requiring further RCB transfusions in this patient subgroup.

Our educational PBM initiative includes the introduction of a periodical reporting system for blood component utilisation, interviews with transfusion experts of all relevant departments and regular educational training programmes to align the individual transfusion decision with the current guidelines and the objective results obtained from several randomised clinical trials as mentioned above [28-32]. After the implementation of the PBM initiative, the proportion of transfused patients and the total amount of blood components applied annually could be noticeably reduced. However, in transfused patients a significant reduction in the mean amount of blood components could not be found, except for a trend with regard to $\mathrm{RBC}$ transfusion. These findings suggest that actually unnecessary transfusions are preferentially avoided by our PBM initiative, whereas appropriate indicated blood transfusions were administered at the same level as before.

In a multicentre study comprising 4,982 ICU patients including $12 \%$ trauma and $20 \%$ post-operative cases, $44.7 \%$ of the patients received RBCs in the ICU and $13.4 \%$ received RBCs after their discharge [35]. In this study, haemoglobin values served as transfusion triggers, varying from $<7$ up to $10 \mathrm{~g} / \mathrm{dl}(8.6 \pm 1.7 \mathrm{~g} / \mathrm{dl})$. The frequency of patients with RBC transfusions in this study (overall $48.2 \%$ ) is comparable to the amount of transfused patients with multiple traumas in our cohort (before PBM 55.6\%, under measures of PBM 49.8\%).

According to a retrospective study in the USA including 5,645 trauma patients, RBC units were used in 8\% (5,219 units, mean consumption 10,7 units per transfused patient), FFP units in $5 \%$ (5,226 units, mean consumption of approximately 19 units) and PLT units in only $3 \%$ of all patients (2,892 units, mean consumption of approximately 17 units). Therefore, the magnitude of blood supply for an individual patient was much higher in this study then that observed in our patient cohort $[12,16]$. Furthermore, nearly two thirds of all RBC transfusions were performed within $24 \mathrm{~h}$ after hospital admission. In 146 out of these 5,645 trauma cases $(2.6 \%)$, patients were supplied with massive transfusion defined as 10 or more RBC units within $24 \mathrm{~h}$ in comparison to approximately $1 \%$ in our retrospective analysis. Most likely due to lower rates of violent crimes in Germany and an overall lower ISS of all trauma patients investigated, our cohort exhibits a slightly lower number of patients with RBC transfusions (5.9$8.1 \%$ with a mean consumption of 5.4-7.1 units per patient) compared with the US data mentioned above. Overall, 3\% of the trauma patients $(531 / 15,457)$ in our study were categorised as multiple trauma patients. Of these, approximately one half received RBC transfusions, and one fifth received FFP transfusions. Only in about $11 \%(60 / 531)$ of these patients, severe haemorrhage made mass transfusions of RBCs necessary. Therefore, our results are more or less consistent with those of the above mentioned study. As shown in our patient cohort with massive transfusion, the RBC/FFP ratio was about 1.0 as expected, whereas the $\mathrm{RBC} /$ PLT ratio was 6.4 indicating a less frequent and potentially delayed decision to add platelet transfusions.
In critically ill patients, including those suffering traumas, the number of RBC transfusions is associated with increased mortality, nosocomial infections, multi-organ dysfunction syndrome, acute respiratory distress syndrome and extended length of stay in the ICU and in the hospital [35-39]. A meta-analysis comprising more than 43,000 trauma cases in 10 studies confirmed these results in general [40]. Therefore, the number of transfused RBCs is discussed as a predictor for worse clinical outcome and as independent risk factor for morbidity and mortality [7, 13, 17, 35, 37-40]. Furthermore, longer RBC storage time $[17,40,41]$ as well as proinflammatory and immunomodulatory effects are discussed as further 'determining' factors $[17,36]$.

To this end, the utilisation of blood components - especially $\mathrm{RBC}$ transfusions - should strongly adhere to international guidelines which are based on knowledge of evidence-based medicine. In a recently published study including more than 20,000 trauma patients, Perel et al. [42] found that the association with the all-cause mortality varies with the predicted risk of death. In cases with low predicted risk $(\leq 20 \%)$, transfusions are associated with an increase in mortality. In patients with $>50 \%$ predicted risk of death, transfusions are associated with reduced mortality. Therefore, it can be concluded that high-risk trauma patients will not profit from more restrictive $\mathrm{RBC}$ transfusion strategies. The evaluation of each patient's general condition, accompanying diagnoses and the assessment of the physiological capacity to compensate major blood loss are very important. For example, older patients require more blood components than younger with comparable trauma diagnoses and surgical procedures as shown in our study (fig. 2). This observation might have special impact on transfusion needs in the next decades when considering of the demographic changes expected.

One of the principal aims of PBM is the avoidance of unnecessary blood transfusions [43]. It has to be self-critically noted that the traditional request for RBCs in 'double packs' has not yet been eradicated despite the educational trainings implemented. This is a simple example that the transformation of habits needs patience and persistency.

In conclusion, our retrospective study indicates that educational PBM initiatives improve the awareness that allogeneic blood transfusions are associated with inherent risks beyond transfusiontransmitted infections. Furthermore, we observed a decrease in transfusion recipients and with some restrictions a reduction in RBC consumption by trend.

The application of blood components should be monitored as a quality-assured element of general hospital care in all supra-regional centres of the German TraumaNetwork DGU to verify the effectiveness of any kind of PBM measures. A broadly accepted, evidence-based treatment algorithm for all bleeding trauma patients, including those with severe haemorrhage, should be implemented by each hospital as recommended in the European guidelines [13].

\section{Disclosure Statement}

The authors declare no conflict of interests, sponsorships or funding arrangements related to this article. 


\section{References}

1 Ruchholtz S, Mand C, Lewan U, Debus F, Dankowsk C, AKUT Seering Committee, Kühne C, Siebert H: Regionalisation of trauma care in Germany: the 'TraumaNetwork DGU ${ }^{\circledR}$-Project'. Eur J Trauma Emerg Surg 2012;38:11-17.

2 Neugebauer EAM, Waydhas C, Lendemans S, Rixen D, Eikermann M, Pohlemann T: Clinical practice guideline: the treatment of patients with severe and multiple traumatic injuries. Dtsch Arztebl Int 2012;109:102108.

3 Bundesanstalt für Arbeitsschutz und Arbeitsmedizin: Unfallstatistik: Unfalltote und Unfallverletzte 2011 in Deutschland. www.baua.de/de/Informationen-fuer-diePraxis/Statistiken/Unfaelle/Gesamtunfallgeschehen/pdf/ Unfallstatistik-2011.pdf?_blob=publicationFiled $v=3$.

4 Ruchholtz S, Pehle B, Lewan U, Lefering R, Müller N, Oberbeck R, Waydhas C: The emergency room transfusion score (ETS): prediction of blood transfusion requirement in initial resuscitation after severe trauma. Transfus Med 2006;16:49-56.

5 Kuhne CA, Zettl RP, Fischbacher M, Lefering R, Ruchholtz S: Emergency Transfusion Score (ETS): a useful instrument for prediction of blood transfusion requirement in severely injured patients. World J Surg 2008; 32:1183-1188.

6 Cotton BA, Gunter OL, Isbell J, Au BK, Robertson AM, Morris JA, St. Jacques P, Young PP: Damage control hematology: the impact of a trauma exsanguination protocol on survival and blood product utilization. J Trauma 2008;64:1177-1183.

7 Cushing M, Shaz BH: Blood transfusion in trauma patients: unresolved questions. Minerva Anestesiol 2011; 77:349-359.

8 Hess JR: Blood and coagulation support in trauma care. Hematology 2007;2007:187-191.

9 Holcomb JB, Hess JR: Early massive trauma transfusion: state of the art. J Trauma 2006;60(suppl 6):S1-S2.

10 Holcomb JB, Jenkins D, Rhee P, Johannigman J, Mahoney P, Mehta S, Cox ED, Gehrke MJ, Beilman GJ, Schreiber M, Flaherty SF, Grathwohl KW, Spinella PC, Perkins JG, Beekley AC, McMullin NR, Park MS, Gonzalez EA, Wade CE, Dubick MA, Schwab CW, Moore FA, Champion HR, Hoyt DB, Hess JR: Damage control resuscitation: directly addressing the early coagulopathy of trauma. J Trauma 2007;62:307-310.

11 Holcomb JB: Optimal use of blood products in severely injured trauma patients. Hematology 2010;2010:465469.

12 Murthi SB, Dutton RP, Edelman BB, Scalea TM, Hess JR: Transfusion medicine in trauma patients. Expert Rev Hamatol 2008;1:99-109.

13 Spahn DR, Bouillon B, Cerny V, Coats TJ, Duranteau J, Fernández-Mondéjar E, Filipescu D, Hunt BJ, Komadina R, Nardi G, Neugebauer E, Ozier Y, Riddez L, Schultz A, Vincent JL, Rossaint JL: Management of bleeding and coagulopathy following major trauma: an updated European guideline. Crit Care 2013;17:R76.

14 Curry N, Stanworth S, Hopewell S, Dorée C, Brohi K, Hyde C: Trauma-Induced coagulopathy - a review of the systematic reviews: is there sufficient evidence to guide clinical transfusion practice? Transfus Med Rev 2011;25:217-231

15 Meißner A, Schlenke P: Massive bleeding and massive transfusion. Transfus Med Hemother 2013;39:73-84.

16 Como JJ, Dutton RP, Scalea TM, Edelman BB, Hess JR: Blood transfusion rates in the care of acute trauma. Transfusion 2004;44:809-813.
17 Napolitano LM, Kurek S, Luchette FA, Corwin HL, Barie PS, Tisherman SA, PC Hebert, Anderson GL, Bard MR, Bromberg W, Chiu WC, Cipolle MD, Clancy KD, Diebel L, Hoff WS, Hughes M, Munshi I, Nayduch D, Sandhu R, Yelon JA, for the American College of Critical Care Medicine of the Society of Critical Care Medicine and the Eastern Association for Surgery of Trauma Practice Management Workgroup: Clinical practice guideline: red blood cell transfusion in adult trauma and critical care. Crit Care Med 2009;37:31243157.

18 Balogh ZJ, Reumann MK, Gruen RL, Mayer-Kuckuk P, Schuetz MA, Harris IA, Gabbe BJ, Bhandari M: Advances and future directions for management of trauma patients with musculoskeletal injuries. Lancet 2012;380:1109-1119.

19 Fudickar A, Hörle K, Wiltfang J, Bein B: The Effect of the WHO Surgical Safety Checklist on complication rate and communication. Dtsch Arztebl Int 2012;109: 695-701.

20 Geissler RG, Franz D, Buddendick H, Krakowitzky P, Bunzemeier H, Roeder N, Van Aken H, Kessler T, Berdel W, Sibrowski W, Schlenke P: Retrospective analysis of the blood component utilization in a university hospital of maximum medical care. Transfus Med Hemother 2012;39:29-138.

21 Roeder N, Siebers L, Frie M, Bunzemeier H: DRG-Akzeptanz verbessern - Kliniker erreichen mit klinischen Leistungsgruppen. Das Krankenhaus 2006;5:390-401.

22 Helling J, Bunzemeier H, Fiori W, Siebers L, Brüning K, Gaber A, Frie M, Babapirali J, Roeder N: Klinische Leistungsgruppen - Update und Ausblick. Das Krankenhaus 2009;9:857-862.

23 Fisher RA: On the interpretation of $\chi^{2}$ from contin gency tables, and the calculation of P. J R Statist Soc 1922;85:87-94.

24 Plackett RL: Karl Pearson and the chi-squared test. Int Stat Rev1983;51:59-72.

25 Mann H, Whitney D: On a test of whether one of two random variables is stochastically larger than the other. Ann Math Stat 1947;18:50-60.

26 Tay SY, Sloan EP, Zun L, Zaret P: Comparison of the New Injury Severity Score and the Injury Severity Score. J Trauma 2004;56:162-164.

27 Sise RG, Calvo RY, Spain DA, Weiser TG, Staudenmayer KL: The epidemiology of trauma-related mortality in the United States from 2002 to 2010. J Trauma Acute Care Surg 2014;76:913-920.

28 Hébert PC, Wells G, Blajchman MA, Marshall J, Martin C, Pagliarello G, Tweeddale M, Schweitzer I, Yetisir E, the Transfusion Requirements in Critical Care Investigators for the Canadian Critical Care Trials Group: A multicenter, randomized, controlled clinical trial of transfusion requirements in critical care. N Engl J Med 1999;340:409-417.

29 Lacroix J, Hébert PC, Hutchison JS, Hume HA, Tucci M, Ducruet T, Gauvin F, Collet JP, Toledano BJ, Robillard P, Joffe A, Biarent D, Meert K, Peters MJ; TRIPICU Investigators; Canadian Critical Care Trials Group; Pediatric Acute Lung Injury and Sepsis Investigators Network: Transfusion strategies for patients in pediatric intensive care units. N Engl J Med 2007;356: 1609-1619.
0 Carson JL, Terrin ML, Noveck H, Sanders DW, Chaitman BR, Rhoads GG, Nemo G, Dragert K, Beaupre L, Hildebrand K, Macaulay W, Lewis C, Cook DR, Dobbin G, Zakriya KJ, Apple FS, Horney RA, Magaziner J, for the FOCUS Investigators: Liberal or restrictive transfusion in high-risk patients after hip surgery. N Engl J Med 2011;365:2453-2462.

31 Hajjar LA, Vincent JL, Galas FR, Nakamura RE, Silva CM, Santos MH, Fukushima J, Kalil Filho R, Sierra DB, Lopes NH, Mauad T, Roquim AC, Sundin MR, Leão WC, Almeida JP, Pomerantzeff PM, Dallan LO, Jatene FB, Stolf NAG, Auler JO Jr: Transfusion requirements after cardiac surgery. JAMA 2010;304:1559-1567.

32 Villanueva C, Colomo A, Bosch A, Concepción M, Hernandez-Gea V, Aracil C, Graupera I, Poca M, Alvarez-Urturi C, Gordillo J, Guarner-Argente C, Santaló M, Muñiz E, Guarner C.: Transfusion strategies for acute upper gastrointestinal bleeding. N Engl J Med 2013;368:11-21.

33 Carsons JL, Carless PA, Hébert PC: Outcomes using lower vs higher hemoglobin thresholds for red blood cell transfusion. JAMA 2013;309:83-84.

34 Schlenke P: Patient blood management. Transfusionsmedizin 2014;4:31-45.

35 Corwin HL, Gettinger A, Pearl RG, Fink PM, Levy MM, Abraham E, MacIntyre NR, Shabot M, Duh MS Shapira MJ: The CRIT Study: Anemia and blood transfusion in the critically ill - current clinical practice in the United States. Crit Care Med 2004;32:39-52.

36 McIntyre L, Hebert PC, Wells G, Fergusson D, Marshall J, Yetisir E, Blajchman MJ, for the Canadian Critical Care Trial Group: Is a restrictive transfusion strategy safe for resuscitated and critically ill trauma patients? J Trauma 2004;57:563-568.

37 Huber-Wagner S, Qvick M, Mussack T, Euler E, Kay MV, Mutschler W, Kanz KG, Working Group on Polytrauma of the German Trauma Society (DGU): Massive blood transfusion and outcome in 1062 polytrauma patients: a prospective study based on the Trauma Registry of the German Trauma Society. Vox Sang 2007;92:69-78.

38 Goodnough LT: Blood management: transfusion medicine comes of age. Lancet 2012:381:1791-1792.

39 Goodnough LT, Levy JH, Murphy MF: Concepts of blood transfusion in adults. Lancet 2012:381:18451854.

40 Marik PE, Corwin HL: Efficacy of red blood cell transfusion in the critically ill: a systematic review of the literature. Crit Care Med 2008;36:2667-2674.

41 Zimrin AB, Hess JR: Current issues relating to the transfusion of stored red blood cells. Vox Sang 2008;96: 93-103.

42 Perel P, Clayton T, Altman DG, Croft P, Douglas I, Hemingway H, Hingorani A, Morley KI, Riley R, Timmis A, Van der Windt D, Roberts I, for the PROGRESS Partnership: Red blood cell transfusion and mortality in trauma patients: risk-stratified analysis of an observational study. PLOS Med 2014;11:e1001664.

43 Spahn DR, Goodnough LT: Alternatives to blood transfusion. Lancet 2013;381:1855-1865. 